\title{
Biyoloji Öğretmen Adaylarının Yakın Çevrelerindeki Ağaçları Tanıma Düzeyleri: Ankara İli Örneği*
}

\section{Gamze MERCAN**, Pınar KÖSEOĞLU***}

Öz: Bu araştırmanın amacı, Hacettepe ve Gazi Üniversiteleri’nin Biyoloji Eğitimi Anabilim Dalı'nda öğrenim gören öğretmen adaylarının yakın çevrelerindeki ağaçları tanıma düzeylerinin incelenmesidir.

Araştırmanın örneklemini, 2015-2016 eğitim öğretim yllında Hacettepe ve Gazi Üniversiteleri’nde Biyoloji Eğitimi Anabilim Dal'ında öğrenim gören toplam 168 (155 Kadın, 13 Erkek) öğrenci oluşturmaktadır. Araştırmada hem nitel hem de nicel analiz teknikleri kullanılmıştır. Veri toplama aracı olarak, biyoloji öğretmen adaylarının yakın çevrelerinde en çok karşılaşabilecekleri ağaç türleri alan uzmanlarının görüşleri alınarak geliştirilmiş Verilen Ağacı Tanı (VAT) Testi ve iki açık uçlu yarı yapılandırılmış sorudan oluşan anket kullanılmıştır. Araştırmanın sonucunda elde edilen nitel veriler MAXQDA 12 Programı ile, nicel veriler ise SPSS 23 Paket Programı ile analiz edilmiştir.

İki kısımdan oluşan ölçme aracı sonucunda elde edilen verilere göre; öğretmen adaylarının yakın çevrelerindeki birçok ağacı tanıma düzeylerinin düşük olduğu sonucu ortaya çıkmıştır. Öğretmen adaylarının VAT Testi’nde yer alan ağaçlardan çam türündeki ağaçları tanıma tanıma düzeylerinin diğerlerine göre daha yüksek olduğu saptanmıştır.

Anahtar Kelimeler: Çevre Eğitimi, Ağaç, Çevre Bilinci, Çevre.

\section{Biology Teacher Candidates’ Identification Levels Of Trees In Their Immediate Surrroundings: Ankara Example}

Abstract: The aim of this study is to examine identification levels of trees in their immediate surroundings of biology teacher candidates' who have been studied in the Department of Biology Education of Hacettepe and Gazi Universities.

\footnotetext{
*Bu çalışma ikinci yazar danışmanlığında birinci yazarın hazırlamış olduğu yüksek lisans tezinden üretilmiştir

**Hacettepe Üniversitesi, Eğitim Fakültesi, Ortaöğretim Fen ve Matematik Alanlar Eğitimi Bölümü, Email: gmercn@gmail.com, Orcid No: 0000-0001-5515-999X.

*** Doç.Dr, Hacettepe Üniversitesi, Eğitim Fakültesi, Ortaöğretim Fen ve Matematik Alanlar Eğitimi Bölümü, Email: koseoglup@gmail.com, Orcid No: 0000-0002-622-7978.
}

$\begin{array}{lll}\text { Gönderim:01.10.2018 Kabul:04.02.2019 Yayın:15.03.2019 } & \text { Ka }\end{array}$


The sample of the study consists of 168 students (155 women, 13 men) who were educated in the Department of biology education at Hacettepe University and Gazi University in the academic year of 2015-2016. In this research both qualitative and quantitative analysis techniques were used. As a data collection tool, a Given Tree Diagnostic (GTD) Test and a semi-structured questionnaire consisting of two open-ended semi-structured questionnaires were used to obtain the opinions of the field experts of the tree species that biology teacher candidates can encounter most frequently in their immediate surroundings. Qualitative data obtained from the study were analyzed with MAXQDA 12 and quantitative data were analyzed with SPSS 23 Package Program.

According to the data obtained as a result of the measurement tool consisting of two parts; many tree recognition levels in the immediate surroundings of teacher candidates were low. It was determined that the level of identification of pine trees from the trees included in the GTD Test was higher than the others.

Keywords: Environmental Education, Tree, Environmental Awareness, Environmental.

\section{Giriş}

Çevre; canlı varlıkların, hayati bağlarla bağlı oldukları, etkiledikleri ve etkilendikleri mekân birimlerine, o canlının/canlılar topluluğunun yaşam ortamı olup, kısaca canlılara etki eden dış etkenlerin tümü olarak tanımlanabilir (Atasoy, 2006). Bu bağlamdan yola çıkılarak; hava, su, toprak, bitki örtüsü, hayvanlar ve dünya üzerinde veya dışında olan her şey çevre kavramının içinde yer almaktadır (Atik ve diğerleri, 2010).

Toplumdaki bireyler, yaşamlarını sürdürebilmek için çevresine müdahale etmekte ve çeşitli etkinliklerle çevresini etkilemektedir. Hızlı nüfus artışı, kontrolsüz kentleşme, sanayileşme, kentlerde meydana gelen hava kirliliği, sularda meydana gelen kirlilik, küresel 1sınma, biyolojik çeşitliliğin azalması örnek olarak verilebilecek günümüzde önem taşıyan temel çevresel problemlerdir (Kocataş, 2006). İnsanoğlunun varlığını sürdürebilmesi, içinde yaşadığı ekosisteme uygun hareket ederek dengenin ve biyolojik çeşitliliğin korunmasına yardımcı olmasına bağlıdır (Külköylüoğlu, 2009). İnsanlığın sahip olduğu ancak önemine tam anlamıyla farkına varamadığı stratejik bir varlık olan biyolojik çeşitliliğin tahrip olması dünya çapında meydana gelecek bir yoksulluğun en büyük sebebi olacaktır. Bu sebepten ötürü biyolojik çeşitlilik dünya mirasının en önemli parçalarından bir tanesini oluşturmaktadır (Çepni, 2005). 
Türkiye’nin Asya ve Avrupa üzerinde bulunan kıtalararası coğrafi konumu, topoğrafik yapısı ve bölgelerdeki iklim etkileri gibi nedenlerden dolayı biyoçeşitlilik açısından zengin bir ülke olup, endemik tür sayısı oldukça fazladır. Yapılan çalışmalar sonucunda, Türkiye florasındaki yer alan yaklaşık 12.000 bitki türden 3.000 üzerinde bitki türünün endemik tür olduğu saptanmıştır. Ayrıca Türkiye florasında yaklaşık 80.000’in üzerinde hayvan türünün bulunduğu ve Dünya üzerinde yer alan 34 küresel yüksek çeşitlilik noktalarından üçünün (Akdeniz, Kafkasya ve İran-Anadolu) Türkiye'de bulunduğu tahmin edilmektedir. Türkiye'nin yoğun doğal kaynak sömürüsü ve insan arazisi kullanımının 10000 yıllık tarihine rağmen, genetik çeşitliliğin bir merkezi olduğundan zengin biyoçeşitlilik mirasına sahiptir. Biyoçeşitlilik, Türkiye'de yaklaşık 20 milyon kırsal insan için önemli kültürel ve ticari değere sahip olduğundan, bu mirasın korunması da büyük bir sorumluluk gerektirmektedir (Şekercioğlu ve diğerleri, 2011; Şenel, 2015).

Biyolojik çeşitlilik açısından bir alanın yönetim ve korunmasının etkili bir şekilde gerçekleştirilebilmesi için bölge halkıyla işbirliğine gidilmesi büyük önem arz etmektedir. Bölge halkının mevcut kaynaklarını koruması ve öğrencilerin çevre koruma bilincine sahip olması hususunda bölgede görev yapan öğretmenlere büyük roller düşmektedir. Bu sebepten dolayı özellikle kırsal kesimlerde görev yapan öğretmenlerin biyolojik çeşitliliği tanıması, incelemesi ve korunması noktasında bilgi sahibi olması, zengin doğal kaynakların korunmasında büyük önem arz etmektedir (Erten, 2004). İyi planlanmış çevre eğitimiyle biyoçeşitlilik hakkında bireylere bilgi verilmesi hedeflenen kalkınma planlarında ortaya konan amaçlara ulaşılmasında oldukça önemli anahtarlardır (Şenel, 2015).

Çevre eğitimi içinde yer alan biyoçeşitlilik eğitiminin amacı; bireyleri biyolojik çeşitliliğin önemi hakkında bilinçlendirerek, bireylerin biyolojik çeşitliliği koruma sorumluluğu ve yeterliliği kazandırılmasıdır. Ancak, Türkiye'de çevre eğitimi, öğrencilerin liseyi bitirene kadar aldıkları biyoloji derslerinden oluştuğundan, bu dersler etkili bir çevre eğitimi için yetersiz kalmaktadır. Öğrenciler, derslerde verilen bilgileri sınava yönelik ezbere dayalı çalıştıklarından, bu bilgiler bireyde istendik davranış değişikliği sağlayamamaktadır (Özcan, 2003). Bu nedenle, biyoçeşitlilik eğitimi ile öğrencilerin bitki ve hayvanları direkt olarak gözlemleyerek yerel türler hakkında bilgi sahibi olması yani etkili bir eğitim süreciyle gerçekleşebilmektedir. Bu da, öğrencilerin doğa ile iç içe etkileşim halinde bulunabildiği, canlıları ve canlılar arasındaki etkileşimleri kendi gözlemleriyle inceleyebildiği eğitim ortamlarıyla mümkün olabilmektedir (Lindemann-Matthies, 2002; Şahin,2018). Tam da bu nokta da, geleceğin öğretmenleri öğretmen adaylarına büyük sorumluluklar düşmektedir. $\mathrm{Bu}$ 
bağlamda, öğretmen adaylarının çevre eğitimi ile ilgili beklentileri karşılayan ders içeriklerinin hazırlanmasında öğretmen adaylarının algılarının tespit edilmesi oldukça önemlidir (Özmen ve Özdemir, 2016).

İlgili alanyazın incelendiğinde konu ile ilgili çalışmalar bulunmaktadır. Farklı yaş grubundaki öğrencileri örneklem olarak seçtikleri bitkileri nasıl gördükleri ve algıladıklarını araştırmak amacıyla yaptıkları çalışmalarda öğrencilerden yaş grubu büyük olanların bitkileri daha iyi tanıdıkları saptanmıştır (Tunnicliffe \& Reiss, 2000; Gatt et al., 2007). İlköğretim 8. Sınıf öğrencilerinin (Ulucanlı, 2009) ve ortaöğretim 9. sınıf öğrencilerinin (Civelek, 2012) çevresinde bulunan bitkilere karşı sahip oldukları farkındalık düzeylerinin düşük olduğu belirlenirken (Nates, et. al., 2010; Yli-Panula \& Matikainen, 2014), lise öğrencilerinin biyoçeşitlilik kaybına yönelik problem algılarının yüksek olduğu (Bilir ve Özbaş, 2017), tıp öğrencilerinin sağlıkta kullanılan bitkileri ve bitkilerin kullanım alanlarını (Aktürk ve diğerleri, 2006), köy halkının ise faydalı bitki türlerini (Guerreco, et. al, 2007) yeteri kadar bilmedikleri, Almanya'daki öğrencilerin, popüler olarak bulunan yerel bitki ve ağaçlardan ağaç türlerini bitki türlerine göre daha iyi bildikleri (Lückman \& Menzel, 2013) saptanmıştır.

Öğretmen adaylarının örneklem olarak belirlendiği araştırmalarda ise; öğretmen adaylarının çevre eğitimi alıp-almama ve kişisel özellikleri değişkenleri ile çevre duyarlılıkları arasında anlamlı farklılık olduğu (Çabuk ve Karacaoğlu, 2003), biyoloji öğretmen adaylarının tohumlu bitkiler konusundaki alternatif kavramlarını saptanmasında öğretmen adaylarının neredeyse yarısının çiçeği tozlaşmaya yardımcı olan renkli çiçek yaprakları olarak algıladığı (Yakışan ve diğerleri, 2007), öğretmen adaylarının biyolojik çeşitlilik eğitimi konusunda bilgi eksiklikleri ve kavram yanılgılarının olduğu, konunun öğretim programındaki yeri ve öğretim yöntem/teknikleri ile ilgili bilgilerinin de yetersiz olduğu (Karabal, 2011; Kılıç ve Dervişoğlu, 2013) saptanmıştır.

Hayati öneme sahip bir konu olan biyolojik çeşitlilik ve bu çeşitliliğin korunması insanların sorumluluğu altında olmasına rağmen, gelecek kuşağın doğayla doğrudan etkileşimin yeterli seviyede olmadığı ve gelecek hakkındaki endişeleri arasında biyoçeşitliliğin azalması yer almaktadır (Bergseng \& Vatn, 2009; Şenel, 2015). Bu nedenle, çevre eğitiminin bir konusu olan biyoçeşitlilik eğitimi biyoloji eğitiminin kavramsal çerçevesinde yer alan en önemli konularından biridir. Biyoçeşitliliğin öneminin bilinerek korunması bireylerin yakın çevrelerini tanımalarıyla başlamaktadır. $\mathrm{Bu}$ kapsamda araştırmanın amacı; Hacettepe ve Gazi Üniversiteleri'nde Biyoloji Eğitimi Anabilim Dal'ında öğrenim gören öğretmen adaylarının yakın çevrelerinde bulunan ağaçları tanıma düzeylerinin 
incelenmesidir. Biyoçeşitlilik kavramını bitki (Ulucanlı, 2009; Civelek, 2012; Yüce, 2017) ya da hayvan türlerine (Şahin, 2018) yönelik olarak ele alındığını göstermektedir. Ancak ilgili alanyazında ağaç türlerini ele alan daha önce yapılmış araştırmaya rastlanılmamıştır ve araştırma sonucunda elde edilen bulguların gelecek araştırmalara rehberlik etmesi açısından önemli olduğu düşünülmektedir.

\section{Araştırmanın Problemi}

Hacettepe ve Gazi Üniversitesi Biyoloji Eğitimi Anabilim Dalı'nda öğrenim gören öğretmen adaylarının yakın çevrelerinde gördükleri ağaçları tanıma düzeyleri nelerdir ve yakın çevrelerinde gördükleri ağaçları tanıma düzeyleri çeşitli değişkenlere (sınıf, doğup büyüdükleri yer, sistematik botanik dersini alıp/almama) göre farklılık göstermekte midir?

\section{Alt Problemler}

1. Biyoloji öğretmen adaylarının yakın çevrelerinde gördükleri ağaçları tanıma düzeyleri nedir?

2. Biyoloji öğretmen adaylarının yakın çevrelerinde gördükleri ağaçları tanıma düzeylerinin okudukları sınıflara göre anlamlı bir farklılık göstermekte midir?

3. Biyoloji öğretmen adaylarının yakın çevrelerinde gördükleri ağaçları tanıma düzeyleri doğup büyüdükleri yere göre anlamlı bir farklılık göstermekte midir?

4. Biyoloji öğretmen adaylarının yakın çevrelerinde gördükleri ağaçları tanıma düzeyleri sistematik botanik dersi alıp almadıklarına göre anlamlı bir farklılık göstermekte midir?

5. Biyoloji öğretmen adaylarının Verilen Ağacı Tanı (VAT) Testi’nde bulunmayan bildikleri ağaç türleri hangileridir?

6. Biyoloji öğretmen adaylarının ağaçları tanımanın önemine ilişkin görüşleri nelerdir?

\section{Yöntem}

$\mathrm{Bu}$ araştırmada, karma yöntem araştırmalarından eş zamanlı (çeşitleme, birleşik) araştırma deseni kullanılmıştır. Eş zamanlı araştırma deseni karma yöntem araştırmalarında en sık kullanılan desenlerden biri olup, bu desende nitel ve nicel araştırma yöntemleri birlikte kullanılarak, farklı araştırma soruları ile elde edilen verilerin çeşitlendirilmesi, karşılaştırılması, bütünleştirilmesi amaçlanmaktadır. Bu sayede, nicel verilerin nitel verilerle ya da nitel verilerin nicel verilerle karşılaştırılmasına, anlamlandırılmasına ve geçerlilik ve güvenirliliğinin sağlanmasına katkıda bulunmaktadır (Creswell, 2014; Yıldırım ve Şimşek, 2018). Araştırma kapsamında biyoloji öğretmen adaylarının yakın çevrenlerindeki ağaçları tanıma düzeyleri nicel verilerin nitel verilerin analizi ile tespit edilmeye çalışılmıştır. 


\section{Çalışma Grubu}

Araştırmanın örneklem seçiminde, araştırmanın aktarılabilirliğinin artırılması amacıyla tipik olarak karşılaşılan olay ve olguları ve bunlara ait değişkenlik gösteren özelliklerini ortaya koyan amaçlı örnekleme yöntemi kullanılmıştır (Yıldırım ve Şimşek, 2018). Bu bağlamda, araştırmanın örneklemini 2015-2016 eğitim öğretim yılı Ankara İl’indeki Hacettepe ve Gazi Üniversiteleri’nin Biyoloji Eğitimi Anabilim Dalı'nda öğrenim gören toplam 168 (155 Kadın, 13 Erkek) öğretmen adayı oluşturmuştur. Araştırmanın örneklemini oluşturan öğrencilerden Hacettepe Üniversitesi'nde okuyanlar 78 kişi (1., 2.,3.,4., 5. Sınıf), Gazi Üniversitesi'nde okuyanlar ise 90 kişi $(1 ., 2 ., 4 ., 5$.$) olup, Gazi Üniversitesi Biyoloji$ Eğitimi Anabilim Dalı'nda bir sene öğrenci alımı gerçekleşmediğinden Gazi Üniversitesi Biyoloji Eğitimi Anabilim Dalı'nda 2015-2016 öğretim yılında okuyan 3. Sınıf bulunmamaktadir.

Araştırmanın örneklemini oluşturan biyoloji öğretmen adaylarının kişisel özelliklerini belirlemek amacıyla hazırlanan sorulara ilişkin elde edilen frekans dağılımlarına ait bulgular (cinsiyet, üniversite ve sınıf) Tablo 1'de verilmiştir.

Tablo 1. Biyoloji Öğretmen Adaylarının Kişisel Özelliklerine Ait Bulgular

\begin{tabular}{|c|c|c|c|}
\hline & & $\mathbf{F}$ & $\%$ \\
\hline \multirow{2}{*}{ Cinsiyet } & Kadın & 155 & 92,3 \\
\hline & Erkek & 13 & 7,7 \\
\hline \multirow{2}{*}{ Üniversite } & Hacettepe Üniversitesi & 78 & 46,4 \\
\hline & Gazi Üniversitesi & 90 & 53,6 \\
\hline \multirow{5}{*}{ Sinif } & 1.sinif & 37 & 22,0 \\
\hline & 2.sinif & 33 & 19,6 \\
\hline & 3.sinif & 19 & 11,3 \\
\hline & 4.sinif & 45 & 26,8 \\
\hline & 5.sinif & 34 & 20,2 \\
\hline
\end{tabular}

Tablo 1’e göre; öğretmen adaylarının \%92,3’ü kadın, \%7,7’si erkektir. Bu öğretmen adaylarından \%46,4’ü Hacettepe Üniversitesi, \%53,6’s1 Gazi Üniversitesi öğrencisi olup bu öğrencilerin \%22'si birinci sınıf, \%19,6's1 ikinci sınıf, \%11,3'ü üçüncü sınıf, \%26,8'i dördüncü sınıf, \%20,2'si beşinci sınıf öğrencisidir.

\section{Veri Toplama Araçları}

Araştırmanın veri toplama araçları; nicel veriler Verilen Ağacı Tanı (VAT) Testi ile nitel veriler ise, yarı yapılandırılmış iki açık uçlu sorudan oluşan anket kullanılmıştır. Araştırmanın amacına yönelik olarak hazırlanan VAT Testi, iki bölümden oluşmakta olup, ilk bölümde kişisel bilgiler, ikinci bölümde ise, biyoloji öğretmen adaylarının yakın çevrelerinde en çok gördükleri 24 ağaçtan oluşmaktadır. Bu testte 24 ağaç fotoğrafi yer almıştır. Testte yer 
alan ağaçlar öğretmen adaylarının çevrelerinde sık karşılaşabilecekleri türlerdir ve alan uzmanlarının görüşleri alınarak belirlenmiştir. Geliştirilen testte her bir ağaca ait dört fotoğraf bulunmakta olup, Türkiye'nin Ağaçları ve Çalıları kitabının yazarı Necati Güvenç Mamıkoğlu'nun arazi gezilerinde çektiği fotoğraflardır. Bu fotoğraflar ağacın uzaktan görünümü, yaprağının, gövdesinin ve varsa meyvesinin net olarak görülebileceği fotoğraflardan oluşmaktadır. VAT’ Testi biyoloji öğretmen adaylarına uygulanmadan iki hafta önce, Hacettepe Üniversitesi Fen Fakültesi Biyoloji Bölümü’nde öğrenim gören 20 öğrenciye uygulanmıştır. Yapılan pilot uygulaması sonucunda, "Çitlembik ve Dişbudak" ağacına ait fotoğraflardan gövdesi ve yaprağıyla ilgili fotoğraflar değiştirilmiştir. VAT Testinin uygulaması; öğretmen adaylarının kişisel bilgileri alındıktan sonra 24 ağaçtan oluşan ikinci bölümde her bir ağaç resmi ayrı sayfada yer almıştır ve öğretmen adaylarından tanıdıkları ağaçların isimlerini cevap anahtarına yazmaları istenmiştir. Öğrencilerin ağaçların isimlerini yazarken bireysel bilgi öz değerlendirilmesini yapması sağlanmıştır. VAT Testi’nin uygulanmasından sonra eş zamanlı olarak yarı yapılandırılmış iki açık uçlu sorudan oluşan anket uygulanmıştır. Uygulama yaklaşık 45 dakikada gerçekleşmiştir.

\section{Verilerin Analizi}

Araştırmada elde edilen veriler nicel ve nitel analiz tekniklerle analiz edilmiştir. Araştırmaya katılan öğretmen adaylarının kişisel bilgi ve demografik özellikleri ve ağaç tanıma seviyesi ile ilgili özelliklerinin analizinde betimsel analiz (frekans ve yüzde) kullanılmıştır. VAT Testi'nden elde edilen puanlar normal dağılım göstermediğinden nonparametrik test yöntemlerinden Mann Whitney U Testi ve Kruskal Wallis H testi ile analiz edilmiştir.

24 ağacın yer aldığı testteki, her bir ağaç 1 puan olarak değerlendirilmiş olup, bütün ağaçları tanıyan biyoloji öğretmen adayının alabileceği maksimum puan 24 olarak belirlenmiştir. Bu bağlamda, biyoloji öğretmen adaylarının ağaç tanıma seviyeleri, elde edilen bulgulara göre; 0-4 ağaç bilenler çok az, 5-9 ağaç bilenler az, 10-14 ağaç bilenler orta, 15-19 ağaç bilenler iyi, 20-24 ağaç bilenler ise ileri seviyede ağaç tanıyanlar olarak sınıflandırılmıştır. Betimsel analizle, araştırmada elde edilen nitel veriler araştırma problem durumuna ilişkin olarak önceden belirlenen temalara göre özetlenerek yorumlanmıştır. Betimsel analiz çerçeve oluşturulup, çerçeveye göre veriler tanımlanmış olup, elde edilen bulgular ise yorumlanarak sonuçlandırılmıştır. Bu bağlamda elde edilen veriler, betimsel analiz için araştırma sorularından yer alan değişkenlerden yola çıkılarak verilerin analizi için oluşturulan tematik çerçeveye göre veriler okunarak düzenlenir. Bu aşamadan sonra da veriler 
tanımlanarak, yorumlanmaktadır (Yıldırım ve Şimşek, 2018). Buna göre, elde edilen veriler, araştırmanın amaçları doğrultusunda, temalar tanımlanarak, MAXQDA 12 programı ile analiz edilmiştir. Ayrıca örneklemde yer alan katılımcıların ifadelerinden alıntılarına da yer verilmiştir.

\section{Bulgular}

Biyoloji öğretmen adaylarının ağaç tanıma puanları Tablo 1.’de ayrıntılı olarak verilmiştir.

Tablo 1. Biyoloji Öğretmen Adaylarının Ağaç Tanıma Puanlarına Ait Bulgular

\begin{tabular}{cccccc}
\hline & $\mathbf{N}$ & Minimum & Maksimum & Ortalama & Standart Sapma \\
\hline $\begin{array}{c}\text { Ağaç Tanıma } \\
\text { Puanı }\end{array}$ & 168 & 0 & 12 & 3,48 & 2,55 \\
\hline
\end{tabular}

Tablo 1'e göre, öğretmen adaylarından VAT Testi'nde yer alan 24 ağaçtan en çok bilen öğretmen adayı 12 ağaç, en az ise hiç ağaç tanınmadığı saptanmıştır. Ayrıca, biyoloji öğretmen adaylarının ağaç tanıma puan ortalamaları 3,48 olarak bulunmuştur.

Biyoloji öğretmen adaylarının yakın çevrelerinde gördükleri ağaçları tanıma düzeylerine ait elde edilen frekans ve yüzde değerlerine ait çoktan aza doğru sıralanmış bulgular Tablo 2.'de verilmiştir.

Tablo 2. Biyoloji Öğretmen Adaylarının Yakın Çevrelerinde Gördükleri Ağaçları Tanıma Düzeylerine Ait Elde Edilen Frekans Ve Yüzde Değerlerine Ait Çoktan Aza Doğru Sıralanmış Bulgular

\begin{tabular}{|c|c|c|c|c|c|}
\hline No & Ăgaç & $\begin{array}{c}\text { Tanıyan } \\
\text { Öğrenci Sayısı } \\
\text { (f) }\end{array}$ & $\%$ & $\begin{array}{c}\text { Tanımayan } \\
\text { Öğrenci Sayısı (f) }\end{array}$ & $\%$ \\
\hline 1 & Karaçam & 93 & 55,36 & 75 & 44,64 \\
\hline 2 & Kızılçam & 79 & 47,02 & 89 & 52,98 \\
\hline 3 & Sarıçam & 76 & 45,24 & 92 & 54,76 \\
\hline 4 & İğde Ăgacı & 64 & 38,10 & 104 & 61,90 \\
\hline 5 & Kavak & 55 & 32,74 & 113 & 67,26 \\
\hline 6 & Ihlamur & 27 & 16,07 & 141 & 83,93 \\
\hline 7 & Meşe & 27 & 16,07 & 141 & 83,93 \\
\hline 8 & Akçaağaç & 26 & 15,48 & 142 & 84,52 \\
\hline 9 & Çinar & 21 & 12,50 & 147 & 87,50 \\
\hline 10 & Sedir & 19 & 11,31 & 149 & 88,69 \\
\hline 11 & Kestane & 18 & 10,71 & 150 & 89,29 \\
\hline 12 & Porsuk & 18 & 10,71 & 150 & 89,29 \\
\hline 13 & Huş Ağacı & 12 & 7,14 & 156 & 92,86 \\
\hline 14 & Ardıç & 11 & 6,55 & 157 & 93,45 \\
\hline 15 & Aksöğüt & 10 & 5,95 & 158 & 94,05 \\
\hline 16 & Göknar & 10 & 5,95 & 158 & 94,05 \\
\hline 17 & Ladin & 9 & 5,36 & 159 & 94,64 \\
\hline 18 & Servi & 4 & 2,38 & 164 & 97,62 \\
\hline 19 & Dişbudak & 3 & 1,79 & 165 & 98,21 \\
\hline 20 & Sı ğla Ağacı & 1 & 0,60 & 167 & 99,40 \\
\hline 21 & Kayın & 1 & 0,60 & 167 & 99,40 \\
\hline
\end{tabular}




\begin{tabular}{lcllll}
\hline 22 & Çitlembik & 0 & 0,00 & 168 & 100,00 \\
\hline 23 & Gürgen & 0 & 0,00 & 168 & 100,00 \\
\hline 24 & Kizılağaç & 0 & 0,00 & 168 & 100,00 \\
\hline
\end{tabular}

Tablo 2.'ye göre; VAT Testi'nde yer alan 24 ağacın tamamını hiçbir öğretmen adayının tanımadığı saptanmaktadır. Öğretmen adaylarının en çok tanıdığı ilk 5 ağaç sırasıyla; karaçam $(\% 55,36)$, kızılçam $(\% 47,02)$, sarıçam $(\% 45,24)$, iğde ağacı $(\% 38,10)$ ve kavak $(\% 32,74)$; en az tanıkları son 5 ağaç ise; aksöğüt $(\% 5,95)$, göknar $(\% 5,95)$, ladin $(\% 5,36)$, servi $(\% 2,38)$ ve dişbudak $(\% 1,79)$ 'dur. Ayrıca, öğretmen adaylarından hiçbirinin bilemediği ağaçlar ise; çitlembik, gürgen ve kızılağaçtır.

Biyoloji öğretmen adaylarının ağaç tanıma seviyelerine ait bulgular Tablo 3.'de verilmiştir.

Tablo 3. Biyoloji Öğretmen Adaylarının A ğaç Tanıma Seviyelerine Ait Bulgular

\begin{tabular}{lcc}
\hline Ăgaç Tanıma Seviyeleri & Frekans & Yüzde \\
\hline Çok Az Bilenler & 122 & 72,6 \\
\hline Az Bilenler & 41 & 24,4 \\
\hline Orta Bilenler & 5 & 3,0 \\
\hline
\end{tabular}

Tablo 3’e göre, öğretmen adaylarının ağaç tanıma seviyelerine ait bulgular; \% 72,6's1 çok az bilenler, \%24,4'ü az bilenler ve \%3'ü çok bilenler olarak saptanmıştır.

Biyoloji öğretmen adaylarının VAT Testi’ndeki ağaçlara verdikleri benzer isimlerden öne çıkanlar Tablo 4.’te verilmiştir.

Tablo 4. Biyoloji Öğretmen Adaylarının VAT Testi'ndeki Ağaçlara Verdikleri Farklı İsimlere Ait Bulgular

\begin{tabular}{llll}
\hline $\begin{array}{c}\text { Sira } \\
\text { No }\end{array}$ & Ağaç İsmi & \multicolumn{2}{c}{$\begin{array}{c}\text { Biyoloji Öğretmen Adaylarının VAT Testi’ndeki } \\
\text { A ğaçlaraVerdikleri Farklı İsimler }\end{array}$} \\
\cline { 3 - 4 } & & \multicolumn{1}{c}{ Hacettepe Üniversitesi } & \multicolumn{1}{c}{ Gazi Üniversitesi } \\
\hline 1 & \multirow{2}{*}{ Sarıçam } & Ardıç, Ladin, Meşe & Ladin, Meşe, Sedir \\
\hline 2 & Aksöğüt & İğde, Zeytin & Ĭğde, Zeytin \\
\hline 3 & Kestane & At Kestanesi, Çınar, Meşe & At Kestanesi, Çınar, Göknar \\
\hline 4 & Sığla Ağacı & Çınar, At Kestanesi & Çınar, At Kestanesi, Meşe \\
\hline 5 & Ardıç & Servi, Çam & Çam, Göknar, Servi \\
\hline 6 & Akçaağaç & Çınar & Çınar, Sedir, Söğüt \\
\hline 7 & Çitlembik & Ardıç, Limon, Zeytin & Limon, Ladin \\
\hline 8 & Çınar & At Kestanesi, Kestane, Palamut & At Kestanesi, Kestane, Meşe \\
\hline 9 & Kayın & At Kestanesi, Kestane, Palamut, & At Kestanesi, Kavak, Palamut, \\
& & Kavak & Fındık \\
\hline 10 & Ladin & Çam, Karaçam & Çam \\
\hline 11 & Ihlamur & Ladin & Erik, Palamut \\
\hline 12 & Gürgen & Kavak & Ladin, Sedir \\
\hline 13 & Kavak & Söğüt & Ihlamur, Selvi, Söğüt \\
\hline 14 & Karaçam & Sarıçam & Göknar, Sedir, Sarıçam \\
\hline 15 & Kızılçam & Çam, Karaçam, Sarıçam & Çınar, Ladir, Sarıçam \\
\hline 16 & Ĭğde Ağacı & Kuşburnu, Zeytin & Kuşburnu, Zeytin \\
\hline 17 & Porsuk & Ateş Dikeni, Kızılcık & Ateşdikeni, Kuşburnu \\
\hline 18 & Huş Ağac1 & Kavak, Söğüt & Söğüt \\
\hline 19 & Meşe ağacı & Palamut, Sedir & Palamut \\
\hline 20 & Sarıçam & Karaçam, Ladin & Karaçam \\
\hline & & &
\end{tabular}




\begin{tabular}{llll}
\hline 21 & Dişbudak & Kayın, Ladin, Köknar & Sedir, Söğüt \\
\hline 22 & Sedir & Köknar, Ladin, Karaçam & Karaçam, Köknar, Palamut \\
\hline 23 & Göknar & Çam, Sedir, Ladin & Çam, Ladin \\
\hline 24 & Kizılağaç & Dut & Dut, Çınar, Ladin, Böğürtlen \\
\hline
\end{tabular}

Tablo 4.’e göre Hacettepe ve Gazi Üniversite'lerinde öğrenim gören öğretmen adaylarının VAT Testi'ndeki ağaçlara verdikleri farklı isimlere ait bulgular incelendiğinde, genelde aynı ağaç isimleri (sarıçama- ladin, meşe; aksöğüte- iğde, zeytin gibi) olduğu görülmektedir.

Biyoloji öğretmen adaylarının VAT Testi'ndeki ağaçları tanıma puanları ile sınıfları arasındaki ilişkiye ait bulgular Tablo 5.'de verilmiştir.

Tablo 5. Biyoloji Öğretmen Adaylarının VAT Testi’ndeki Ağaç Tanıma Puanları İle Sınıfları Arasındaki İlişkiye Ait Bulgular

\begin{tabular}{|c|c|c|c|c|c|c|c|}
\hline & Sinıf & $\mathbf{N}$ & $\begin{array}{l}\text { Sira } \\
\text { Ortalaması }\end{array}$ & & & $\mathbf{P}$ & Fark \\
\hline \multirow{5}{*}{$\begin{array}{l}\text { Ăgaç tanıma } \\
\text { puanı }\end{array}$} & 1.Sinif $f^{(1)}$ & 37 & 70,31 & \multirow{5}{*}{4} & \multirow{5}{*}{27,699} & \multirow{5}{*}{$0,001^{*}$} & $1-4(p=0,003)$ \\
\hline & 2.Sinif $f^{(2)}$ & 33 & 63,97 & & & & $1-5(p=0,001)$ \\
\hline & 3.Sinıf $f^{(3)}$ & 19 & 87,24 & & & & $2-3(p=0,004)$ \\
\hline & 4.Sinif $f^{(4)}$ & 45 & 95,63 & & & & $2-4(p=0,001)$ \\
\hline & 5.Sinıf ${ }^{(5)}$ & 34 & 103,60 & & & & $2-5(p=0,001)$ \\
\hline
\end{tabular}

Tablo 5.'e göre, 4. Sınıftaki öğretmen adaylarının (Sıra Ortalaması: 95,63, p=0,001) 1. Sınıf biyoloji öğretmen adaylarına göre (Sıra Ortalaması: 70,31, p=0,003) daha yüksek puana sahip oldukları saptanmıştır.

Biyoloji öğretmen adaylarının VAT Testi'ndeki ağaçları tanıma puanları ile yaşadıkları yer arasındaki ilişkiye ait bulgular Tablo 6.' da verilmiştir.

Tablo 6. Biyoloji Öğretmen Adaylarının Ağaç Tanıma Puanları İle Doğup Büyüdükleri Yer Arasındaki İlişkiye Ait Bulgular

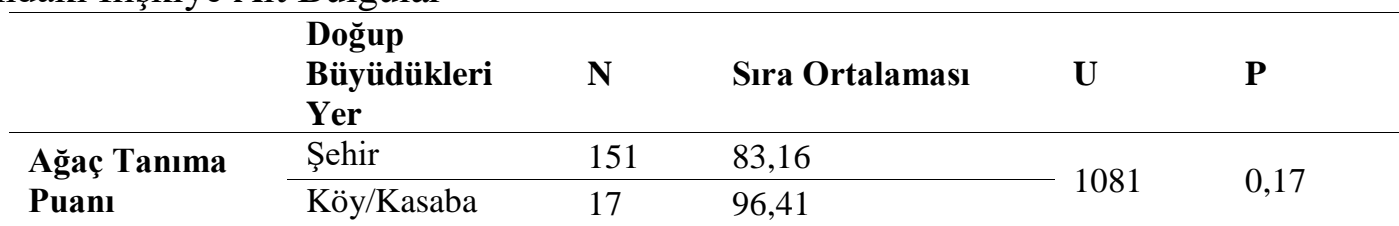

Tablo 6.’ya göre öğretmen adaylarının ağaç tanıma puanları ile doğup büyüdükleri yer arasında $(p=0,17)$ anlamlı farklılık saptanmamıştır $(p>0,05)$.

Biyoloji öğretmen adaylarının VAT Testi'ndeki ağaçları tanıma puanları ile sistematik botanik dersi alıp/ almamaları arasındaki ilişkiye ait bulgular Tablo 7.'de verilmiştir.

Tablo 7. Biyoloji Öğretmen Adaylarının Ağaç Tanıma Puanları İle Sistematik Botanik Dersi Alınıp/Alınmaması Arasındaki İlişkiye Ait Bulgular

$\mathbf{U}$

$\mathbf{P}$ 
YYÜ Eğitim Fakültesi Dergisi (YYU Journal of Education Faculty), 2019; 16(1):538-560, http://efdergi.yyu.edu.tr

ISSN: 1305-020

\begin{tabular}{llllll}
\hline \multicolumn{5}{l}{ Alınmaması } \\
\hline A ğaç tanıma & Evet & 116 & 90,59 & \multirow{2}{*}{2309} & $0,002 *$ \\
puanı & Hayır & 52 & 70,90 & \\
\hline
\end{tabular}

Tablo 7.’e göre, sistematik botanik dersi alan öğretmen adaylarının ağaç tanıma puanlarının (Sıra Ortalaması: 90,59), sistematik botanik dersi almayanlara göre (S1ra Ortalaması: 70,90)daha yüksek puana sahip oldukları saptanmıştır.

VAT Testi'nde bulunmayan biyoloji öğretmen adaylarının bildikleri ağaç türleri Tablo 8.'da verilmiştir.

Tablo 8. VAT Testi’nde Bulunmayan Biyoloji Öğretmen Adaylarının Bildikleri Ağaç Türleri

\begin{tabular}{|c|c|c|c|}
\hline $\begin{array}{l}\text { Sira } \\
\text { No }\end{array}$ & $\begin{array}{l}\text { Biyoloji Öğretmen Adaylarının VAT Testi'nde } \\
\text { Bulunmayan Bildikleri Ağaç Türleri }\end{array}$ & Frekans & $\%$ \\
\hline 1 & Kiraz & 39 & 23,21 \\
\hline 2 & Elma & 38 & 22,62 \\
\hline 3 & Erik & 38 & 22,62 \\
\hline 4 & Armut & 26 & 15,48 \\
\hline 5 & Dut & 23 & 13,69 \\
\hline 6 & Ceviz Ağacı & 18 & 10,71 \\
\hline 7 & Vişne & 16 & 9,52 \\
\hline 8 & Kavak & 15 & 8,93 \\
\hline 9 & Kay1s1 & 12 & 7,14 \\
\hline 10 & Şeftali & 12 & 7,14 \\
\hline 11 & Ladin & 11 & 6,55 \\
\hline 12 & Meşe & 9 & 5,36 \\
\hline 13 & Zeytin & 9 & 5,36 \\
\hline 14 & Köknar & 8 & 4,76 \\
\hline 15 & İncir & 8 & 4,76 \\
\hline 16 & Söğüt & 8 & 4,76 \\
\hline 17 & Portakal & 7 & 4,17 \\
\hline 18 & Limon & 7 & 4,17 \\
\hline 19 & Karaçam & 7 & 4,17 \\
\hline 20 & Ayva & 7 & 4,17 \\
\hline 21 & Çınar & 7 & 4,17 \\
\hline 22 & Palamut & 7 & 4,17 \\
\hline 23 & Findık & 6 & 3,57 \\
\hline 24 & Ardıç & 5 & 2,98 \\
\hline 25 & Nar & 4 & 2,38 \\
\hline 26 & Palmiye & 4 & 2,38 \\
\hline 27 & Ihlamur & 4 & 2,38 \\
\hline 28 & Kestane & 4 & 2,38 \\
\hline 29 & Selvi & 3 & 1,79 \\
\hline 30 & Akçaağaç & 3 & 1,79 \\
\hline 31 & İğde & 3 & 1,79 \\
\hline 32 & Akasya & 3 & 1,79 \\
\hline 33 & Betula & 3 & 1,79 \\
\hline 34 & Kayın & 3 & 1,79 \\
\hline 35 & Muz & 3 & 1,79 \\
\hline
\end{tabular}




\begin{tabular}{llll}
\hline 36 & Sarıçam & 3 & 1,79 \\
\hline 37 & Sedir & 3 & 1,79 \\
\hline 38 & Badem & 3 & 1,79 \\
\hline 39 & Mazı & 3 & 1,79 \\
\hline 40 & Hurma & 3 & 1,79 \\
\hline 41 & Dişbudak & 3 & 1,79 \\
\hline 42 & Sandal Ağacı & 2 & 1,19 \\
\hline 43 & Trompet Ağacı & 2 & 1,19 \\
\hline 44 & Akasya & 2 & 1,19 \\
\hline 45 & Kizılçam & 2 & 1,19 \\
\hline 46 & Keçi Boynuzu & 2 & 1,19 \\
\hline 47 & Gürgen & 2 & 1,19 \\
\hline 48 & At Kestanesi & 2 & 1,19 \\
\hline 49 & Mandalina & 2 & 1,19 \\
\hline
\end{tabular}

Tablo 8.'e göre biyoloji öğretmen adaylarının VAT Testi 'nde bulunmayan en çok bildikleri ilk 5 ağaç sırasıyla; Kiraz $(\% 23,21)$, Elma $(\% 22,62)$, Erik $(\% 22,62)$, Armut $(\% 15,48)$ ve Dut $(\% 13,69)$ olduğu saptanmıştır. Buna göre;, biyoloji öğretmen adaylarının en çok bildikleri ağaçların meyve ağaçları olduğu belirlenmiştir. Ayrıca, biyoloji öğretmen adaylarının en az tanıdıkları (dişbudak) ve hiç tanımadıkları (gürgen) ağaçların isimlerini yazmaları dikkat çekmiştir. Bu bulgudan yola çıkılarak; biyoloji öğretmen adaylarının bazı ağaçların isimlerini bilmelerine rağmen tanıyamadıkları söylenebilir.

Biyoloji öğretmen adaylarının ağaçları tanımanın önemine ilişkin görüşlerine ait bulgular Tablo 9.'da verilmiştir.

Tablo 9. Biyoloji Öğretmen Adaylarının Ağaçları Tanımanın Önemine İlişkin Görüşlerine Ait Bulgular

\begin{tabular}{llll}
\hline $\begin{array}{l}\text { Sira } \\
\text { No }\end{array}$ & Neden Önemli? & Frekans & \% \\
\hline 1 & Yaşanılan Çevreyi Tanıma, Çevre Bilinci & 36 & 21,43 \\
\hline 2 & Meslek, Bölüm ve Botanik Dersi İçin Önemi & 35 & 20,83 \\
\hline 3 & Ağaçlardan Faydalanmak, Faydalarını Öğrenmek ve Bilmek & 31 & 18,45 \\
\hline 4 & Bilinçli Ağaç Dikmek, Doğanın Dengesini Korumak & 26 & 15,48 \\
\hline 5 & Cevap Verilmemiş & 23 & 13,69 \\
\hline 6 & İlgim Yok, Önemli Değil & 14 & 8,33 \\
\hline 7 & Genel Kültür & 11 & 6,55 \\
\hline 8 & Hastalıklar İçin, İlaç Yapımında Kullanılmaktadır & 9 & 5,36 \\
\hline 9 & Oksijen Kaynağ1 & 8 & 4,76 \\
\hline 10 & İnsan Yaşamı & 7 & 4,17 \\
\hline 11 & Ekonomik ve Çevresel Açıdan Önemli & 5 & 2,98 \\
\hline 12 & Bitkilerle İlgilenmeyi Sevdiğim İçin & 4 & 2,38 \\
\hline 13 & Bilimsel Çalışmalar & 3 & 1,79 \\
\hline 14 & Öğrencilere Ağaç Özelliklerini Daha İyi Aktarabilmek & 2 & 1,19 \\
\hline 15 & Erozyonu Önler & 2 & 1,19 \\
\hline
\end{tabular}


Tablo 9.’a göre, öğretmen adaylarının ağaçları tanımanın önemine ilişkin görüşlerine ait bulgular sırasıyla; yaşanılan çevreyi tanıma, çevre bilinci $(\% 21,43)$, meslek, bölüm ve botanik dersi için önemi $(20,83)$ ve ağaçlardan faydalanmak, faydalarını öğrenmek ve bilmek $(\% 18,45)$ 'tir.

\section{Tartışma}

Araştırma kapsamında biyoloji öğretmen adaylarının yakın çevrelerindeki ağaçları tanıma düzeylerinin düşük olduğu saptanmıştır. Ulucanlı (2009) ve Civelek (2012)'in farklı örneklemlerle gerçekleştirdikleri ve yakın çevredeki bitkileri tanıma düzeylerini inceledikleri araştırmaların sonuçları da benzerdir ve araştırmayı desteklemektedir. Bununla birlikte Bastı (2010), Demirezen (2012), Şenel (2015)'in ve Şahin (2018)'in farklı örneklem gruplarının çevrelerindeki biyoçeşitlilikle ilgili farkındalık düzeyleri de düşük olarak saptanmış olduğundan bu araştırma sonuçlarıyla benzerdir.

Öğretmen adaylarının ağaçları tanıma puanları ile sınıfları arasındaki anlamlı farklılık saptanmış olup, 4.Sınıftaki biyoloji öğretmen adaylarının 1. Sınıftakilere göre daha yüksek puana sahip oldukları saptanmıştır. Bu bulgu, öğretmen adaylarının ağaçları tanıma puanları ile sistematik botanik dersi alıp/almamaları arasında anlamlı farklılık saptanmış olup, sistematik botanik dersi alanların ağaç tanıma puanlarının almayanlara göre daha yüksek olduğu sonucuyla örtüşmektedir. Şahin ve diğerleri (2004), Kang ve diğerleri (2005), Keser (2008), Yüce (2017), Şahin (2018)'in farklı örneklem gruplarıyla yaptıkları araştırmada üst sınıftaki öğrencilerin alt sınıftakilere göre müfredatta yer alan çevre ve biyoçeşitlilik konularının yer alması sonucunda çevreyi tanıma düzeylerini arttırdığını saptamaları araştırmanın bulgularıyla örtüşmektedir. Bizerril (2004) farklı yaş gruplarıyla yaptıkları araştırmada öğrencilerin, tanımadığı ve farkında olmadığı şeyleri korumadığını da belirtmiştir. Ancak, Ürey ve Şahin (2010), Gök (2012), Özsevgeç ve Artun (2012) ve Çavuş (2013) tarafından farklı örneklem gruplarıyla yapılan araştırmalarda bilgi ağırlıklı çevreye yönelik eğitimin bireylerde günlük hayatla ilişkilendirilmediğinden çevreyi tanıma düzeyleri üzerinde etkisi olmadığını saptadıklarından araştırmanın sonuçlarını desteklememektedir.

Öğretmen adaylarının ağaç tanıma puanları ile doğup büyüdükleri yer (köy/şehir) arasında anlamlı farklılık saptanmamıştır. Ancak, Civelek (2012), Lückmann ve Menzel (2013)'ın farklı örneklemlerle yaptıkları çalışmalarda da yakın çevredeki bitki ve ağaç tanıma düzeylerinin köylerde yaşayanların şehir merkezlerindekilerine göre; Türküm (1998) ve Şahin (2018)'in yakın çevredeki biyoçeşitlilik ile ilgili farkındalıkları incelediği araştırmada da, hayatlarının bir bölümünde evlerinde ya da bahçelerinde hayvan besleyenlerin beslemeyenlere 
göre hayvanları tanıma düzeyleri daha yüksek çıkması araştırmanın sonuçlarını desteklememektedir.

Araştırmanın örnekleminin VAT Testi’nde bulunmayan en çok bildikleri ağaçların meyve ağaçları olduğu saptanmıştır. Bu bulguya göre, öğretmen adaylarının yakın çevrelerini tanıma düzeylerinde antroposentrik (insan merkezli) çevre davranışlarına sahip oldukları, yani çevreyi sadece kendine hizmet eden bir araç olarak gördükleri söylenebilir. Halbuki insan çevre ile vardır ve onun bir parçasıdır. Öğretmen adaylarının benmerkezci yaklaşımdan uzaklaşması ve bireyleri ekosentrik (çevre merkezli) bakış açısına sahip kı1ması biyoçeşitliliğin korunmasında büyük önem taşımaktadır (Bizerill, 2004). Ulucanlı (2009), Bastı (2010), Civelek (2012) Türkmen ve diğerleri (2016) ve Şahin (2018) farklı örneklem gruplarıyla yaptıkları araştırmada, bireylerin daha çok evlerinde tükettikleri meyveleri tanıma düzeylerinin yüksek olduğu, tüketmedikleri ağaçları tanımadıkları; Nates ve diğerleri (2010) yaptığı araştırmada ise, bireylerin tükettikleri bitkileri, faydalandıkları ve sevdikleri hayvanları tanıma düzeylerinin yüksek olması araştırmanın sonuçlarını desteklemektedir.

Araştırmanın örnekleminin ağaçları tanımanın önemine ilişkin görüşleri; yaşanılan çevreyi tanıma, çevre bilinci, meslek, bölüm ve botanik dersi için önemi ve ağaçlardan faydalanmak, faydalarını öğrenmek ve bilmek olduğu saptanmıştır. Civelek (2012) farklı örneklem gruplarıyla yaptıkları araştırmada bireyler için bitki tanımanın önemine ilişkin görüşleri sağlık açısından fayda ve zararının bilinmesine yönelik olarak saptanmış olup, araştırmanın sonuçlarıyla kısmen örtüşmektedir.

\section{Sonuç}

Araştırmada elde edilen sonuçlar aşağıda verilmiştir:

- VAT Testi’nde yer alan 24 ağacın tamamını hiçbir biyoloji öğretmen adayının tanımadığı saptanmaktadır. Biyoloji öğretmen adaylarının en çok tanıdığı ilk 5 ağaç sırasıyla; karaçam $(\% 55,36)$, kızılçam $(\% 47,02)$, sarıçam $(\% 45,24)$, iğde ağacı $(\% 38,10)$ ve kavak $(\% 32,74)$; en az tanıkları son 5 ağaç ise; aksögüt $(\% 5,95)$, göknar $(\% 5,95)$, ladin $(\% 5,36)$, servi $(\% 2,38)$ ve dişbudak $(\% 1,79)$ 'dur. Ayrıca, biyoloji öğretmen adaylarından hiçbirinin bilemediği ağaçlar ise; çitlembik, gürgen ve kızılağaçtır.

- Araştırmanın örnekleminin ağaç tanıma seviyelerine ait bulgular; \%72,6's1 çok az bilenler, \%24,4'ü az bilenler ve \%3'ü çok bilenler olarak saptanmıştır. 
- Araştırmanın örnekleminin VAT Testi’nde yer alan 24 ağaçtan en çok bilen öğretmen adayı 12 ağaç, en az ise hiç ağaç tanınmadığı saptanmıştır. Ayrıca, öğretmen adaylarının ağaç tanıma puan ortalamaları 3,48 olarak bulunmuştur.

- Araştırmanın örnekleminin VAT Testi’ndeki ağaçlara verdikleri farklı isimlere ait bulgular incelendiğinde, genelde aynı ağaç isimleri (sarıçama ladin, meşe; aksögüte, iğde, zeytin gibi) olduğu görülmektedir.

- Araştırmanın örnekleminin VAT Testi’ndeki ağaçları tanıma puanları ile sınıfları arasındaki anlamlı farklılık saptanmış olup, 4. Sınıftaki öğretmen adaylarının (Sıra Ortalaması: 95,63, p=0,001) 1. Sınıf öğretmen adaylarına göre (Sira Ortalaması: 70,31, p=0,003) daha yüksek puana sahip oldukları belirlenmiştir.

- Araştırmanın örnekleminin ağaç tanıma puanları ile doğup büyüdükleri yer arasında $(p=0,17)$ anlamlı farklılık saptanmamıştır $(\mathrm{p}>0,05)$.

- Araştırmanın örnekleminin VAT Testi’ndeki ağaçları tanıma puanları ile sistematik botanik dersi alıp/almamaları arasında anlamlı farklılık saptanmış olup, sistematik botanik dersi alan öğretmen adaylarının ağaç tanıma puanlarının (Sıra Ortalaması: 90,59), sistematik botanik dersi almayanlara göre (S1ra Ortalamas1: 70,90) daha yüksek puana sahip oldukları belirlenmiştir.

- Verilen Ağacı Tanı (VAT) Testi 'nde bulunmayan öğretmen adaylarının en çok bildikleri ilk 5 ağaç sırasıyla; Kiraz $(\% 23,21)$, Elma $(\% 22,62)$, Erik $(\% 22,62)$, Armut $(\% 15,48)$ ve Dut $(\% 13,69)$ olduğu saptanmıştır. Buna göre; öğretmen adaylarının en çok bildikleri ağaçların meyve ağaçları olduğu belirlenmiştir.

- Araştırmanın örnekleminin ağaçları tanımanın önemine ilişkin görüşlerine ait bulgular sırasıyla; yaşanılan çevreyi tanıma, çevre bilinci $(\% 21,43)$, meslek, bölüm ve botanik dersi için önemi $(20,83)$ ve ağaçlardan faydalanmak, faydalarını öğrenmek ve bilmek $(\% 18,45)$ 'tir.

\section{Öneriler}

- Araştırma sonucunda biyoloji öğretmen adaylarının yakın çevrelerindeki ağaçları tanıma düzeylerinin düşük olması nedeniyle, öğretmen adaylarının bitki ve ağaçları tanımaya yönelik eğitimleri artırılarak, yakın çevrelerini tanımalarını sağlanabilir. $\mathrm{Bu}$ bağlamda, öğretmen adaylarının yakın çevrelerini tanımaları için, okul dışı öğrenim ortamlarında çevre gezileri yapılabilir.

- Öğretmen adaylarının öğrenim gördükleri yerleşkelerde bulunan ağaçlara kare kod uygulaması kullanılarak ağaçlara ait bilgiler etiketlere yazılabilir. Öğretmen adayları 
da, akı1lı telefonlarına kare kod uygulaması yükleyerek etiketlerden yakın çevrelerindeki ağaçları tanımaları sağlanabilir.

- Biyoloji Öğretmenliği Lisans programındaki botanik, genel biyoloji, çevre eğitimi, okul dışı öğrenme ortamları gibi derslerin içerikleri gözden geçirilerek özellikle çevredeki ağaç ve bitkileri tanıtıcı bilgilere yer verilmelidir.

\section{Teşekkür}

Araştırma kapsamında, VAT Testi’nin geliştirilmesinde desteklerini esirgemeyen, Ankara Üniversitesi Sistematik Botanik Uzmanı Selçuk Tuğrul KÖRÜKLÜ’ ye, Kırsal Çevre ve Ormancılık Sorunları Derneği Başkanı Ahmet DEMİRBAŞ ve İsmail ŞENEL’e,

VAT Testi'ndeki ağaç fotoğraflarını daha önce hiçbir yerde kullanmadığı arşivinden veren “Türkiye’nin Ağaçları ve Çalıları” kitabının yazarı Necati Güvenç MAMIKOĞLU’na,

Araştırmanın istatiksel analiz kısmında katkıları için "Selim KIZILKAYA"ya teşekkür ederiz.

\section{Makalenin Bilimdeki Konumu}

Matematik ve Fen Bilimleri Eğitimi/Biyoloji Eğitimi

\section{Makalenin Bilimdeki Özgünlüğü}

İlgili alanyazında, biyoçeşitliliğin önemli bir konusu olan ağaçları tanımalarına yönelik ulusal ve uluslararası çalışmaların yok denecek kadar az sayıda olması, elde edilen bulguların, bu kapsamdaki eksikleri gidermek için rehberlik edeceği düşünülmektedir. Ayrıca, geleceğin biyoloji öğretmenleri olan öğretmen adaylarının çevrelerinde gördükleri ağaç türlerini tanımalarının sağlanması, gelecek nesillerin ülkemizin sahip olduğu biyolojik zenginliğin farkına varmalarında ve çevre sorunlarının azaltılmasında oldukça önemlidir.

\section{Kaynakça}

Atasoy, E. (2006). Çevre için eğitim çocuk doğa etkileşimi. Bursa: Ezgi Kitabevi.

Aktürk, Z., Dağdeviren, N., Yıldırım, T., Yılmazer, A., Bulut, F., Subaşı, B. (2006). Tıp öğrencileri bitkileri ne kadar tanıyor? Tıp fakültesi birinci ve altıncı sınıf öğrencileri arasında bitkilerin ve sağlıktaki kullanım alanlarının bilinme durumları. Genel Tıp Dergisi, 16(3), 101-106.

Atik, A. D., Öztekin, M., Erkoç, F. (2010). Biyoçeşitlilik ve Türkiye'deki endemik bitkilere örnekler. Gazi Eğitim Fakültesi Dergisi, 30(1), 219-240.

Bergseng, E., Vatn, A. (2009). Why protection of biodiversity creates conflict-Some evidence from the Nordic countries, Journal of Forest Economics, 15(3), 147-165. 
Bizerill, M. X. A. (2004). Children's perceptions of Brazil Ian Cerrado landscapes and biodiversity. The Journal of En vironmental Education, 35, 47-58.

Bilir, A., Özbaş, S. (2017). Lise öğrencilerinin küresel ve yerel biyoçeşitlilik kaybına yönelik problem algıs1. Atatürk Üniversitesi Sosyal Bilimler Enstitüsü Dergisi, 21(1), 97-108.

Civelek, S. (2012). Ortaöğretim 9. sınıf öğrencilerinin çevrelerindeki bitkileri tanıma düzeyleri: Trabzon ili örneği (Yayınlanmamış yüksek lisans tezi), Karadeniz Teknik Üniversitesi Eğitim Bilimleri Enstitüsü, Trabzon.

Creswell, J. W. (2014). Research design: Qualitative, quantitative, and mixed methods approaches. California: Sage.

Çabuk, B., Karacaoğlu, C. (2003). Üniversite öğrencilerinin çevre duyarlılıklarının incelenmesi. Ankara Üniversitesi Eğitim Bilimleri Enstitüsü Dergisi, 36,189-198.

Çavuş, A. (2013). Ortaokul 7. sınıf fen ve teknoloji dersinin çevre eğitimi açısından etkiliğine ilişkin öğretmen görüşlerinin değerlendirilmesi (Bingöl İli Örneği). (Yayınlanmamış yüksek lisans tezi). İnönü Üniversitesi, Sosyal Bilimler Enstitüsü, Malatya.

Çepni, S. (2005). Kuramdan uygulamaya fen ve teknoloji öğretimi. Ankara: Pegem Akademi.

Çevre Bakanlığı (2001). Ulusal biyolojik çeşitlilik stratejisi ve eylem planı. Ankara: Çevre Bakanlığı Yayınları.

Çevre ve Orman Bakanlığı (2011). Ulusal iklim değişikliği strateji belgesi 2010-2020. Ankara: Çevre ve Orman Bakanlığı Yayınları.

Demirezen, S. (2012). İlköğretim öğrencilerinin yakın çevresindeki biyolojik zenginliklerinin farkındalıkları Kars ili örneği (Yayınlanmamış Yüksek Lisans Tezi). Kafkas Üniversitesi Fen Bilimleri Enstitüsü, Kars.

Erten, S. (2004). Çevre eğitimi ve çevre bilinci nedir, çevre eğitimi nasıl olmalıdır?. Çevre ve Insan Dergisi, 65(66), 1-13.

Gatt, S., Tunnicliffe, S., Borgl, K., Lautier, K., (2007). Young maltese childern’s ideas about plants. Journal Biology Education, 41(3), 117-121.

Gök, E. (2012). İlköğretim öğrencilerinin çevre bilgisi ve çevresel tutumları üzerine alan araştırması (Yayınlanmamış yüksek lisans tezi). Necmettin Erbakan Üniversitesi Eğitim Bilimleri Enstitüsü, Konya.

Guerrero, A., Garcia, V., Ramos, M., Casas, A. (2007). Knowledege and use value of plant species in a raramuri community: A gender perspective for conservation, springer science business media, llc. Human Ecology, 36, 259-272. 
Hughes, J.B., Ives, A.R., Norberg, J. (2007). Do species intractions buffer environmental variation (in theory). Biodiversity and Ecosystem Functioning ;Synthesis and Perspectives, 34(4),92-101.

Kang, S., Scharmann, L. C., Noh, T. (2005). Examining students' views on the nature of science: results from Korean 6th, 8th and 10th grades. Science Education, 89, 314-334.

Karabal, M. (2011). Fen ve teknoloji öğretmen adaylarının biyolojik çeşitliliğe ilişkin görüşleri (Yayınlanmamış Yüksek Lisans Tezi). Mehmet Akif Ersoy Üniversitesi Fen Bilimleri Entitüsü, Burdur.

Keser, S. (2008). Fen bilgisi öğretmen adaylarının çevreye karşı tutumları (Yayınlanmamış Yüksek Lisans Tezi). Abant İzzet Baysal Üniversitesi Eğitim Bilimleri Enstitüsü, Bolu.

Kılıç, A. (2007). Sınıf öğretmeni yetiştirme programında yer alan derslerin öğrenilme düzeyleri. Elektronik Sosyal Bilimler Dergisi, 19(6), 136-145.

Kılıç, D. S., Dervişoğlu, S. (2013).Öğretmen adaylarının biyolojik çeşitliliğin öğretimine ilişkin pedagojik alan bilgileri, tutumları ve kaygıları. Eğitim ve Öğretim Araştırmaları Dergisi, 2(1), 100-109.

Külköylüoğlu, O. (2009). Çevre ve çevre: insan-doğa ilişkisi. Bolu: Abant İzzet Baysal Üniversitesi Döner Sermaye Basımevi.

Lindemann-Matthies, P. (2002). The influence of an educational program on children's perception of biodiversity. The Journal of Enviromental Education. 33(2), 22-31.

Lückman, K., Menzel, S. (2013). Herbs versus trees: influences on teenagers' knowledge of plant species. Journal of Biological Education, 48(2), 80-90.

Nates, J., Campos, C., Lindemann-Matthies, P. (2010). Student' perception of plant and animal species: A case study from Rural Argentina. Enviromental Education and Communication, 9, 131-141.

Özcan, N., (2003). A group of students' and teachers' perceptions with respect to biology education at high school level (Unpublished Ph.D.Thesis). Middle East Technical Universty Instute of Education Science, Ankara.

Özsevgeç, T., Artun, H. (2012). İlköğretim öğrencilerinin çevreye yönelik tutumlarına etki eden faktörlerin değerlendirilmesi . 11. Ulusal Sınıf Öğretmenliği Eğitimi Sempozyumu, 24-26 Mayıs 2012, Rize.

Şahin, N. F., Cerrah, L., Saka, A., Şahin, B. (2004). Yüksek öğretimde öğrenci merkezli çevre eğitimi dersine yönelik bir uygulama. Gazi Ĕ̆itim Fakültesi Dergisi, 24(3), 113-128. 
Şahin, Ü.,G. (2018). Ortaokul öğrencilerinin biyoçeşitlilik konusunda farkındalıklarının çeşitli değişkenlere göre incelenmesi (Yayınlanmamış Yüksek Lisans Tezi). Akdeniz Üniversitesi Eğitim Bilimleri Enstütüsü, Antalya.

Şekercioğlu, Ç. H., Anderson, S., Akçay, E., Bilgin, R., Can, Ö. E., Semiz, G., Tavşanoğlu, Ç., Yokeş, M., B., Soyumert, A., İpekdal, K., Sağlam, İ. K., Yücel, M., Dalfes, N. (2011). Turkey’s globally important biodiversity in crisis. Biological Conservation, 144(12), 2752-2769.

Şenel, T. (2015). Analysis of unıversity students' perception of and attitudes towards biodiversity (Unpublished Master Thesis). Istanbul Technical Unıversity Eurasia Institute Of Earth Sciences, İstanbul.

Tunnicliffe, S., Reiss, M. (2000). Building a model of the environment: How the children see plants?. Journal of Biological Education, 34(4), 172-178.

Türkmen, H., Topkaç, D., D.,Yamık, G.,A. (2016). Informal öğrenme ortamlarına yapılan gezilerin canlıları sınıflandırılması ve yaşadığımız çevre konusunun öğrenilmesine etkisi: tabiat tarihi müzesi ve botanik bahçesi örneği. Ege Eğitim Dergisi, 17(1), 174197.

Türküm, A., S. (1998). Çă̆daş toplumda çevre sorunları ve çevre bilinci. Anadolu Üniversitesi. G. Can (Ed.). Çağdaş Yaşam Çağdaş İnsan. Anadolu Ü. A.Ö.F. İlköğretim Öğretmenliği Lisans Tamamlama Programı, Eskişehir, 165-181.

Ulucanlı, F.H. (2009). İlköğretim öğrencilerinin çevrelerindeki bitkileri tanıma düzeyleri: Bolu ili örneği (Yayınlanmamış yüksek lisans tezi). Abant İzzet Baysal Üniversitesi Sosyal Bilimler Enstitüsü, Bolu.

Ürey, M., Şahin, B. (2010). Akademik personelin çevre sorunları ve çevre eğitimine yönelik duygu, düşünce ve davranışlarının değerlendirilmesi. Çukurova Üniversitesi Eğitim Fakültesi Dergisi, 3(38), 134-149.

Yakışan, M., Selvi, M., Yürük, N. (2007). Biyoloji öğretmen adaylarının tohumlu bitkiler hakkındaki alternatif kavramları. Gazi Üniversitesi Gazi Eğitim Fakültesi Biyoloji Eğitimi Türk Fen Eğitimi Dergisi, 4(1), 60-79.

Yıldırım, A., Şimşek, H. (2018). Sosyal bilimlerde nitel araştırma yöntemleri. Ankara: Seçkin Yayincilik.

Yli-Panula, E., Matikainen, E. (2014). Students and student teachers' ability to name animals in ecosystems: a perspective of animal knowledge and biodiversity. Journal of Baltic Science Education, 13(4), 559-572. 
Yüce, M. (2017). Fen bilimleri öğretmen adaylarının yakın çevresindeki bitkileri tanıma düzeyleri (Yayınlanmamış Yüksek Lisans Tezi). Akdeniz Üniversitesi Eğitim Bilimleri Enstütüsü, Ankara.

\section{Summary}

\section{Statement of Problem}

The aim of this study is to examine identification levels of trees in their immediate surroundings of pre-service biology teachers' who have been studied in the Department of Biology Education of Hacettepe and Gazi Universities. The research questions are as follows:

What are identification levels of trees in their immediate surroundings of pre-service biology teachers' who have been studied in the Department of Biology Education of Hacettepe and Gazi Universities and are identification levels of trees in their immediate surroundings according to various variables (class, birthplace, whether to take the systematic Botanical course or not)?

The sub-problems are as follows.

1. What are the levels of identifications of trees that biology teacher candidates see in their immediate surroundings?

2. Is there a significant difference between identification levels of the trees that biology teacher candidates see in their immediate surroundings compared to the classes they read?

3. Does the level of identification of trees seen by biology teacher candidates in their immediate surroundings differ significantly from where they were born and grew up?

4. Does the level of identification of trees seen by biology teacher candidates in their immediate surroundings differ significantly depending on whether they take systematic Botanical courses?

5. What are the tree species that biology teacher candidates know when they aren't in Given Tree Diagnostic (GTD) Test?

6. What are the views of biology teacher candidates about the importance of identication trees?

\section{Method}

In this study, a simultaneous (diversification, united) research pattern was used from mixed method research. Simultaneously research pattern is one of the most frequently used patterns in mixed method research, and it is aimed to use qualitative and quantitative research methods together with different research questions to diversify, compare, and integrate the 
data obtained. In this way, it contributes to the comparison, meaning and validity of quantitative data with qualitative data and qualitative data (Creswell, 2014; Y1ldırım \& Şimşek, 2018).

\section{Findings}

The findings obtained within the scope of the research are as follows:

- The sample of the study is \%92.3 female and \%7.7 male. Among these, \%46.4 are students of Hacettepe University and \% 53.6 are students of Gazi University. \% 22 of these students are first-class, \% 19.6 second-class, \%11.3 third-class, \%26.8 fourthclass, \%20.2 fifth-class.

- It is determined that no biology teacher candidate knows all 24 trees in the GTD test. The first 5 trees to be recognized by biology teachers were black pine (55.36\%), red pine (\%47.02), yellow pine (\%45.24), elaeagnus (\%38.10) and populus (\%32.74) respectively; the last 5 trees were white willow (\%5.95), abies (\%5.95), spruce (\%5.36), cupressus (\%2.38) and fraxinus (\%1.79). In addition, the trees that none of the biology teacher candidates know; hackberry, hornbeam and alnus.

- Findings of biology teacher candidates' tree identification levels; \% 72.6 of those who know very little, \% 24.4 of those who know less and \%3 of those who were found to be very connoisseurs.

- It was found that 24 trees in the GTD test, one of the biology teacher candidates, were the most knowledgeable teacher candidates; 12 trees and at least no trees were identicated. In addition, tree identification scores of biology teacher candidates were 3.48 .

- The sample of the research is examined by the findings of different names given to the trees in the GTD test, it is observed that there are generally the same tree names (yellow pine called spruce; white willow called eleagnus etc.).

- The sample of the study was found to have a significant difference between the trees identification scores in the GTD test and the classes. Biology teacher candidates in the first class (rank mean: 95.63, p=0.001). It was determined that they had higher scores according to class biology teacher candidates (rank average: 70,31, p=0,003).

- There was no significant difference between the tree identification scores and the place where they were born $(p=0.17)(p>0.05)$. 
- The sample of the study was determined to have a significant difference between the identification scores of trees in the GTD Test and whether or not they took a systematic botanical course.

- The first 5 trees that biology teacher candidates knew most were cherry (23.21\%), apple (22.62\%), plum (22.62\%), pear (15.48\%) and mulberry (13.69\%) respectively, which were not found in the GTD test. According to this, it has been determined that the trees that biology teacher candidates know most are fruit trees.

- The findings of biology teacher candidates regarding the importance of recognizing trees are; environmental awareness (21,43\%), environmental awareness (21,43\%), the importance of profession, department and botanical lessons (20,83\%) and the use of trees, learning and knowing the benefits (18,45\%).

\section{Discussion and Conclusion}

The findings from the research revealed that had low levels of identification of the trees in their surroundings. Ulucanlı (2009) and Civelek (2012) investigated identification levels of nearby plants with different samples because the results were similar. However, the level of awareness about biodiversity around the different sample groups of Basti (2010), Demirezen (2012), Şenel (2015) and Şahin (2018) has been low as compared to results of this research. There was a significant difference between the tree recognition scores of biology teacher candidates and their classes. Biology teacher candidates in first class. They were found to have a higher score than those in the classroom. This finding was found to be a significant difference between the tree recognition scores of biology teacher candidates and whether or not they take a systematic botanical course and the results of the systematic botanic courses are consistent with the results that the tree recognition scores are higher than those who don’t those. Şahin et al. (2004), Kang et al. (2005), Keser (2008), Yüce (2017), Şahin (2018) with different sample groups, the findings of the study show that the upper class students have increased their environmental awareness levels by taking into consideration the environmental and biodiversity issues in the curriculum compared to the lower class students. However, research conducted with different sample groups by Uvey and Şahin (2010), Gök (2012), Özsevcet and Artun (2012) and Çavuş (2013) doesn't support the results of the research as they found that the education of environmental education has no effect on the conversion of information into behaviour and the Association of information with daily life.

There was no significant difference between the tree recognition scores of biology teacher candidates and the location (village/city) where they were born and raised. However, 
according to the studies carried out by Civelek (2012), Lückmann and Münzel (2013) with different samples, the levels of the plant and tree recognition levels in the nearby environment were compared with those in the villages of the inhabitants of the city centres. Şahin (2018) examined the awareness of biodiversity in the nearby environment, in part of their lives, animal recognition levels higher than those who don't feed animals in their homes or gardens don't support the results of the study.It was found that the trees they knew most were fruit trees. Ulucanlı (2009), Bastı (2010), Civelek (2012) Türkmen and others (2016) and Şahin (2018) in the research with different sample groups, the results of the research are supported by the individuals who don't know the trees they consume and the ones who don't consume; Nates and others (2010) who don't know trees, plants, animals.

Opinions on the recognition of the importance of the tree of the sample of the study; recognition of the environment we live in, environmental awareness, occupation, partition, and trees for botany to know the importance and learn the benefits and make use of, that it is revealed. Civelek (2012) study in their research with different sample groups, that their views on the importance of plant recognition for individuals. So they have been determined for the purpose of knowing the benefits and harm in terms of health and partially coincide with the results of the research. 